\title{
Educação Especial na Educação Escolar Indigena: contribuições da pesquisadora Marilda Moraes Garcia Bruno
}

\section{Special Education in the Indigenous School Education: contributions of the researcher Marilda Moraes Garcia}

Bruno

\section{Resumo}

Neste artigo apresentamos os resultados de uma pesquisa que objetivou apresentar as contribuições que a pesquisadora Marilda Moraes Garcia Bruno trouxe para a interface da educação especial na educação escolar indígena no Brasil. Como metodologia utilizamos a abordagem bibliométrica e adotamos como unidade de análise os trabalhos encontrados no Catálogo de Dissertações e Teses da Coordenação de Aperfeiçoamento de Pessoal de Nível Superior (Capes), pois esse banco de dados é um dos principais meios de divulgação de produções científicas Stricto Sensu no Brasil. O estudo bibliométrico permitiu afirmar que são poucas as pesquisas realizadas no país que discutem a interface da educação especial na educação escolar indígena (14 trabalhos). Entretanto, cabe destacar que a pesquisadora Marilda Moraes Garcia Bruno orientou 50\% das produções encontradas. Esse dado revela que além de ser pesquisadora referência na área da educação especial também contribuiu para que a interface da educação especial com a educação escolar indígena fosse construída e discutida pela academia.

Palavras-chave: Educação Especial. Educação Escolar Indígena. Estudo Bibliométrico.

\section{Abstract}

\footnotetext{
${ }^{1}$ Doutora em Educação Especial pela Universidade Federal de São Carlos (UFSCar), Mestre em Educação pela Universidade Federal da Grande Dourados (UFGD) e Pedagoga pela UFGD. Docente da Universidade Federal de Minas Gerais. E-mail: micheledesa20@hotmail.com. 2 Doutora em Educação pela Universidade de São Paulo (USP), Mestre em Educação Especial pela Universidade Federal de São Carlos (UFSCar) e Pedagoga pela Pontificia Universidade Católica de Campinas (PUC-Campinas). Docente da Universidade Federal de São Carlos. Email: caiado.katia@gmail.com.
} 
In this article we present the results of a research that aimed at presenting the contributions that the researcher Marilda Moraes Garcia Bruno brought to the interface of the special education for indigenous school education. The methodology used was the bibliometric approach and the papers found in the Catalog of the Coordination for the Improvement of Higher Education Personnel (Capes) were adopted as our analyses unit, since this data base is one of the main means of the Stricto Sensu scientific productions disseminations. The bibliometric study helped to assert that there are very few researches carried out in the country which discuss the interface of the special education for indigenous school education (14 papers). However, it must be noted that the researcher Marilda Moraes Garcia Bruno advised 50\% of the productions found. This data shows that, besides being the reference researcher in the special education area, she also contributed so that the interface of the special education with the indigenous school education was built and discussed in the academy.

Keywords: Special Education. Indigenous School Education. Bibliometric Study.

\section{Introdução}

A educação especial como atendimento das pessoas com deficiência teve início, no Brasil, no século XIX. As ações neste momento histórico eram isoladas e visavam atender pessoas com deficiências sensoriais, físicas e mentais. Essas primeiras iniciativas não estavam integradas as politicas de educação, apenas em meados do século XX, especificamente com a promulgação da Lei de Diretrizes e Bases da Educação (LDB/1961) é discutida oficialmente e instituída a denominação "educação dos excepcionais" neste documento. (MAZZOTTA, 2005).

Nas últimas décadas a educação especial vem passando por diversas reformulações no que se refere às suas práticas e configuração nas políticas educacionais. Num primeiro momento enfatizou o atendimento clínicoterapêutico ofertado em instituições tradicionais de assistência às pessoas com deficiência mental, físicas e sensoriais (APAE, PESTALOZZI, etc.), o qual tinha caráter assistencialista e visão segregativa.

Na Constituição Cidadã, de 1988, a pessoa com deficiência passa a ser sujeito de direito. No Art. 205 é estabelecido que “[...] a educação é um direito de todos e dever do Estado e da família [...]" como também garante no Art. 208 "III - atendimento educacional especializado aos portadores de deficiência, 
preferencialmente na rede regular de ensino" (BRASIL, 1988). Porém, será a partir da década de 1990, com o movimento da Educação Inclusiva, divulgado pela Declaração Mundial de Educação para Todos (Jomtiem, 1990) e apresentado especificamente pela Declaração de Salamanca (1994) que reorganiza o papel da educação especial no Brasil.

Com essa nova configuração da educação especial na perspectiva da educação inclusiva as pessoas com deficiência passam a ter o direito de frequentar preferencialmente o ensino regular e a garantia que os serviços da educação especial estejam disponíveis para auxiliar na sua inclusão. Neste momento, a educação especial passa a ser considerada uma modalidade de ensino que perpassa todos os níveis, etapas e modalidades, realiza o atendimento educacional especializado e disponibiliza recursos e serviços nas turmas do ensino regular (BRASIL, 2008).

Percebe-se também que a educação especial passa a ampliar o seu atendimento e serviços as outras modalidades de ensino, como por exemplo a educação do campo, educação escolar indígena, educação escolar quilombola dentre outras. Pela primeira vez na política de educação é reconhecido que as pessoas com deficiência estão em diversos contextos culturais e educacionais e precisam dos serviços da educação especial para auxiliar na sua escolarização.

Neste sentido, a Convenção sobre os Direitos das Pessoas com Deficiência (realizada em Nova York no ano de 2007), promulgada pelo Decreto $\mathrm{n}^{\circ}$. 6.949 de 2009 (BRASIL, 2009), foi o primeiro documento que apontou preocupações com as dificeis situações enfrentadas por pessoas com deficiência que estão sujeitas a formas múltiplas de discriminação, em virtude de sua cor, sexo, origem nacional étnica, nativas dentre outras. Reconhece a necessidade de promover e proteger os direitos humanos de todas as pessoas com deficiência, inclusive daquelas que requerem maior apoio. Este documento reconheceu que a pessoa com deficiência pode sofrer múltiplas discriminações devido à associação da deficiência a uma origem étnica ou nativa, como a indigena, por exemplo. 
No contexto acadêmico percebemos que são poucos os pesquisadores que estão se debruçando a estudar como acontece a interface da educação especial em outras modalidades de ensino ligadas ao campo. No Brasil, temos alguns pesquisadores que estão direcionando suas pesquisas para essa interface, no caso da educação especial com a educação escolar indígena podemos destacar a professora e pesquisadora Marilda Moraes Garcia Bruno. Assim, neste artigo pretendemos apresentar as contribuições que a pesquisadora Marilda Bruno trouxe para a interface da educação especial com a educação escolar indígena no Brasil.

A seguir apresentaremos como a interface aparece na política educacional, em seguida os dados encontrados no Catálogo de Dissertações e Teses da Coordenação de Aperfeiçoamento de Pessoal de Nivel Superior (Capes) sobre a produção científica que discute a interface da educação especial na educação escolar indígena e finalmente, as produções e contribuições da pesquisadora Marilda Moraes Garcia Bruno, foco deste estudo.

\section{Educação Especial na Educação Escolar Indígena na politica educacional brasileira}

Pela legislação atual, a educação especial e educação escolar indigena são consideradas um direito social e nas últimas décadas, diversos documentos vêm norteando estas duas modalidades da educação. Dessa forma, torna-se fundamental apresentar os conceitos encontrados nas políticas sobre a educação especial e educação escolar indigena e como essa interface se configura no texto legal.

A educação especial é entendida na Lei de Diretrizes e Bases da Educação Nacional n. ${ }^{0}$ 9.394/96 (LDB/1996) como modalidade de educação transversal que perpassa todos os niveis de ensino, sendo oferecida preferencialmente na rede regular de ensino para os alunos com necessidades especiais.

Na Política Nacional de Educação Especial na Perspectiva da Educação 
Inclusiva (BRASIL, 2008) a educação especial se constitui como uma modalidade de ensino que perpassa todos os niveis, etapas e modalidades, realiza o Atendimento Educacional Especializado (AEE), identifica as necessidades educacionais especiais, disponibiliza os serviços e recursos próprios desse atendimento e orienta os alunos e seus professores quanto a sua utilização nas salas comuns do ensino regular.

Nesta perspectiva, a educação especial passa a integrar a proposta pedagógica da escola regular, promovendo o atendimento às necessidades educacionais especiais de alunos com deficiência, transtornos globais de desenvolvimento e altas habilidades/superdotação, assim considerados neste documento:

[...] considera-se pessoa com deficiência aquela que tem impedimentos de longo prazo, de natureza física, mental ou sensorial que, em interação com diversas barreiras, podem ter restringida sua participação plena e efetiva na escola e na sociedade. Os alunos com transtornos globais do desenvolvimento são aqueles que apresentam alterações qualitativas das interações sociais recíprocas e na comunicação, um repertório de interesses e atividades restrito, estereotipado e repetitivo. Incluem-se nesse grupo alunos com autismo, sindromes do espectro do autismo e psicose infantil. Alunos com altas habilidades/superdotação demonstram potencial elevado em qualquer uma das seguintes áreas, isoladas ou combinadas: intelectual, acadêmica, liderança, psicomotricidade e artes, além de apresentar grande criatividade, envolvimento na aprendizagem e realização de tarefas em áreas de seu interesse (BRASIL, 2008, p. 09).

No caso da educação escolar indigena, esta foi garantida na Constituição Federal de 1988 (C.F/1988), a qual no Art. 10 assegurou “[...] às comunidades indígenas também a utilização de suas línguas maternas e processos próprios de aprendizagem” (BRASIL, 1988).

A educação escolar indigena, almejada por diferentes comunidades e assegurada constitucionalmente veio apontar um novo modelo de educação escolar, marcada pelo direito à diferença. Neste contexto, a LBD/1996 garante, no Art. 79, para estas comunidades a oferta de uma educação escolar bilingue e intercultural e o respeito aos processos próprios de aprendizagem de cada comunidade indígena no processo escolar (BRASIL, 1996). De acordo com esta legislação (Art. 78) a educação escolar indígena tem por objetivo: 
I - proporcionar aos índios, suas comunidades e povos, a recuperação de suas memórias históricas; a reafirmação de suas identidades étnicas; a valorização de suas línguas e ciências;

II - garantir aos índios, suas comunidades e povos, o acesso às informações, conhecimentos técnicos e científicos da sociedade nacional e demais sociedades indígenas e não- índias. (BRASIL, 1996)

O Referencial Curricular Nacional para as escolas indígenas - RCNEI (BRASIL, 1998) se concretiza como um documento importante para a educação escolar indigena, uma vez que traz informações sobre os novos parâmetros, faz orientações curriculares e procedimentos pedagógicos em diversas áreas do saber, discute a atuação e a formação dos professores indígenas. Este documento define quatro características da escola indígena: comunitária, intercultural, bilíngue/multilíngue, específica e diferenciada.

De acordo com Referencial ela é comunitária porque é conduzida pela comunidade indigena de acordo com seus projetos, suas concepções e seus princípios; é intercultural porque deve reconhecer e manter a diversidade cultural e linguística; é bilingue/multilingue porque as tradições culturais, os conhecimentos acumulados, a educação das gerações mais novas, as crenças, o pensamento e a práticas religiosas, as representações simbólicas, a organização política, os projetos de futuro, enfim, a reprodução sociocultural das sociedades indigenas é, na maioria dos casos, manifestados através do uso de mais de uma lingua; é especifica e diferenciada "Porque é concebida e planejada como reflexo das aspirações particulares de cada povo indigena e com autonomia em relação a determinados aspectos que regem o funcionamento e orientação da escola não-indígena” (BRASIL, 1998, p. 25).

Com relação à educação especial na educação escolar indígena, recentemente as politicas públicas de educação vêm considerando essa interface. A Politica Nacional de Educação Especial na Perspectiva da Educação Inclusiva (BRASIL, 2008) foi o primeiro documento nacional, referente à educação especial, que levanta o debate sobre a interface da educação especial na educação escolar indígena. Este documento aponta:

A interface da educação especial na educação indígena, do campo e quilombola deve assegurar que os recursos, serviços, e atendimento educacional especializado estejam presentes nos projetos 
pedagógicos construídos com base nas diferenças socioculturais desses grupos (BRASIL, 2008, p.19).

No Plano Nacional de Educação (PNE/2014-2014), na versão final aprovada no Congresso Nacional, ficou estabelecido na Meta 4:

4.3) implantar, ao longo deste PNE, salas de recursos multifuncionais e fomentar a formação continuada de professores e professoras para o atendimento educacional especializado nas escolas urbanas, do campo, indigenas e de comunidades quilombolas. (BRASIL, 2014).

Observa-se que na versão final do texto apresenta avanço quando considera que os povos indígenas também têm alunos que são público alvo da educação especial. Porém, apresenta falhas quando reduz a educação especial as salas de recursos multifuncionais; quando não especifica quem serão os professores formados no AEE para atuar dentro das comunidades indigenas e fere o princípio de autonomia da escola indígena quando transfere o modelo instituído da educação especial da população não indígena.

No documento Diretrizes Curriculares Nacionais para Educação Escolar Indígena na Educação Básica ${ }^{3}$ (aprovado em 2012) é discutida a interface da educação especial na educação escolar indigena. Dentre vários aspectos, o documento aponta que as politicas direcionadas para o atendimento especializado precisam ser elaboradas e colocadas em prática segundo a realidade sociocultural de cada comunidade. É enfatizado no documento que o sistema de ensino deve assegurar a acessibilidade aos alunos indígenas, público alvo da educação especial, por meio da oferta de

\footnotetext{
3 "A construção dessas Diretrizes se deu em diálogo instituído entre o CNE, a Comissão Nacional de Educação Escolar Indígena do Ministério da Educação (CNEEI/MEC) e o Grupo de Trabalho Técnico Multidisciplinar, criado pela Portaria ${ }^{\circ} 593$, de 16 de dezembro de 2010, no âmbito da Secretaria de Educação, Alfabetização e Diversidade (SECAD) do MEC3. Foram relevantes, ainda, nesse processo as manifestações apresentadas nos dois seminários sobre Diretrizes para a Educação Escolar Indigena realizados pelo CNE, ocorridos em 2011 e 2012, em Brasília, bem como as contribuições provindas da reunião técnica ocorrida durante o último desses seminários. Nesse sentido, estas Diretrizes constituem o resultado de um trabalho coletivo, que expressa o compromisso de representantes de diferentes esferas governamentais e não governamentais, com participação marcante de educadores indigenas, envolvidos com a promoção da justiça social e a defesa dos direitos dos povos indígenas na construção de projetos escolares diferenciados, que contribuam para a afirmação de suas identidades étnicas e sua inserção digna na sociedade brasileira.” (BRASIL, 2013, p. 376).
} 
prédios escolares, mobiliários adequados, transporte escolar, recursos humanos e outros materiais adaptados às necessidades desses alunos (BRASIL, 2013).

As Diretrizes Curriculares Nacionais para Educação Escolar Indígena apresentam também avanços no que se refere a identificação das necessidades educacionais especiais:

$\mathrm{Na}$ identificação das necessidades educacionais especiais dos estudantes indigenas, além da experiência dos professores indigenas, da opinião da família, das questões culturais, a escola indígena deve contar com assessoramento técnico especializado e o apoio da equipe responsável pela Educação Especial em parceria com as instâncias administrativas da Educação Escolar Indígena nos sistemas de ensino (BRASIL, 2013, p. 390).

Observa-se que para identificar as necessidades educativas dos alunos é considerada a opinião da família, dos professores indigenas e as questões culturais de cada comunidade. Isso é importante porque a concepção de necessidade e/ou deficiência que eles têm, em alguns casos, difere do conceito da sociedade não indígena que ainda foca nos aspectos patológicos.

No documento é enfatizado ainda:

O atendimento educacional especializado na Educação Escolar Indigena deve assegurar a igualdade de condições para o acesso, permanência e conclusão com sucesso dos estudantes que demandam esse atendimento. Para efetivar essas condições faz-se necessária a ação conjunta e coordenada da família, da escola, dos sistemas de ensino e de outras instituições da área da saúde e do desenvolvimento social (BRASIL, 2013, p. 390).

De modo geral, percebe-se que as pessoas indigenas com deficiência, mesmo que timidamente, ganharam visibilidade nas políticas educacionais, porém cabe apresentarmos como a academia e pesquisadores discutem essa temática no contexto da ciência.

\section{Caminhos metodológicos}


Para este trabalho utilizamos a pesquisa bibliométrica sobre a produção científica que discute a temática da interface da educação especial na educação escolar indigena. Segundo Hayashi et al (2005, p. 15) o uso da bibliometria pode ser vantajoso nos seguintes aspectos: “[...] na contribuição às avaliações de pesquisa na universidade; na avaliação de grupos de pesquisa da mesma área; na avaliação da contribuição de pesquisadores para determinada área, e na classificação entre instituições, etc”. Para este o estudo, a bibliometria contribuiu para localizar os estudos desenvolvidos sobre a interface como também possibilitou identificar as contribuições de pesquisadores para essa temática.

Adotamos como unidade de análise os trabalhos encontrados no Catálogo de Dissertações e Teses da Coordenação de Aperfeiçoamento de Pessoal de Nivel Superior (Capes). A escolha desse banco de dados se justifica pelo fato de ser um dos principais meios de divulgação de produções científicas Stricto Sensu no Brasil.

O Catálogo de Dissertações e Teses ${ }^{4}$ foi disponibilizado no ano de 2002 pela Capes. O Catálogo concede as referências e resumos das teses e dissertações defendidas nos programas de pós-graduação do Brasil e tem como principal objetivo facilitar o acesso a estas informações. As informações bibliográficas dos trabalhos defendidos em programas de mestrado e doutorado são fornecidas diretamente para Capes pelos programas de pósgraduação do país. Essa ferramenta permite a pesquisa por autor, título, instituição, nivel e ano de defesa do trabalho, palavras-chave, linha pesquisa, área de conhecimento, programa, agência financiadora, nível.

O levantamento nesse banco de dados aconteceu por meio dos seguintes descritores: índio deficiência (1 trabalho); indigena deficiência (1 trabalho); indígena educação especial (3 trabalhos); educação escolar indígena educação especial (1 trabalho); educação especial educação escolar indigena (5 trabalhos); educação escolar indigena atendimento educacional especializado (2 trabalhos) e educação indigena inclusão escolar (4 trabalhos). Após

\footnotetext{
${ }^{4}$ As informações referentes ao Catálogo de Dissertações e Teses da Capes foram retiradas do site <http://sdi.capes.gov.br/banco-de-teses/02_bt_sobre.html>.
} 
eliminada a duplicidade de produções existentes em mais de um descritor, realizou-se a leitura dos resumos de todas as produções que totalizou 14 trabalhos sobre a temática escolhida.

Com base nesse universo e por meio das informações encontradas no banco, realizamos o presente balanço das produções. Para desenvolver as análises apresentadas a seguir, escolhemos como categorias de análise: ano de produção; pesquisadores (autores e orientadores); nível de pós-graduação (mestrado e doutorado); vinculação institucional (autores e orientadores e programa.

\section{Educação Especial na Educação Escolar Indigena na produção científica: achados da pesquisa}

O primeiro aspecto a ser analisado neste trabalho refere-se ao período abrangido pela produção acadêmica do Catálogo de Teses e Dissertação da Capes, que tem início em 1987, quando foram resgatados e incluídos no banco referências de trabalhos defendidos, até o ano de 2018. Na figura 1 podemos observar a distribuição no período.

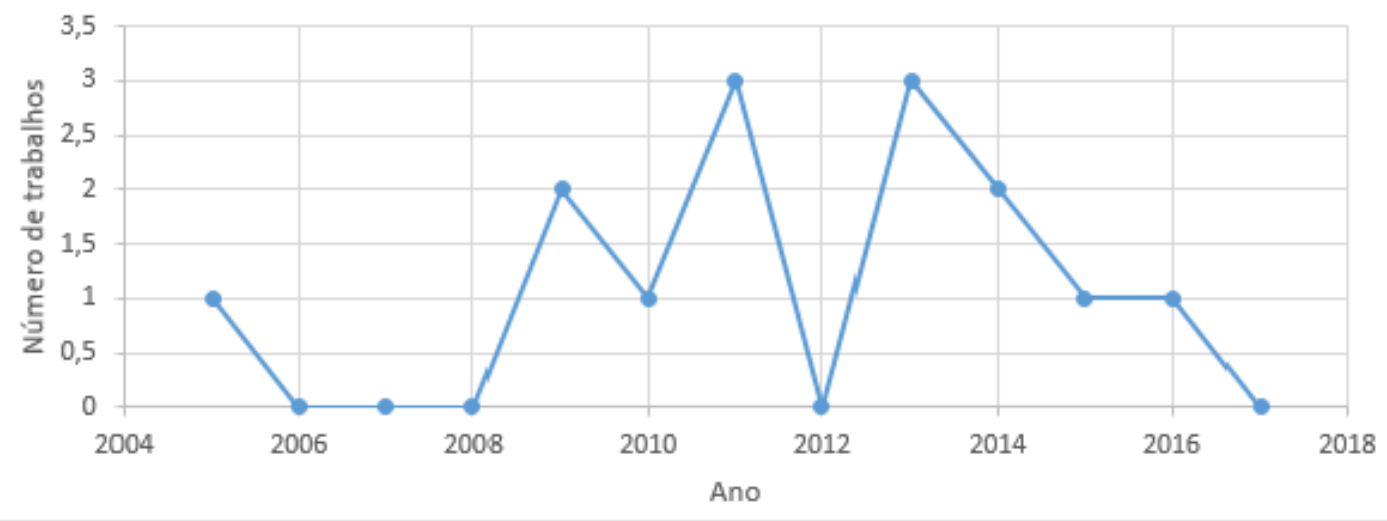

Figura 1 - Distribuição de dissertações e teses disponíveis no Catálogo de Dissertação e Teses da Capes 
A figura 1 mostra o período que foi encontrado produção acadêmica sobre a temática (2005 a 2018). Neste período foram achados um total 14 trabalhos de mestrado e doutorado que retrataram a interface da educação especial com a educação escolar indígena. Os resultados não apresentam distribuição uniforme dos trabalhos no período analisado, tem um trabalho em 2005, nenhum no período de 2006 a 2008 e evidenciou aumento a partir de 2009. Os anos que tiveram mais trabalhos defendidos foram 2011 e 2013 , ambos anos com 3 trabalhos cada.

Na figura 2 observamos a distribuição dos 14 trabalhos por nível. Verificamos que 11 trabalhos são de mestrado e 3 de doutorado. Este resultado demonstra que o tema está sendo mais pesquisado no nível de mestrado.

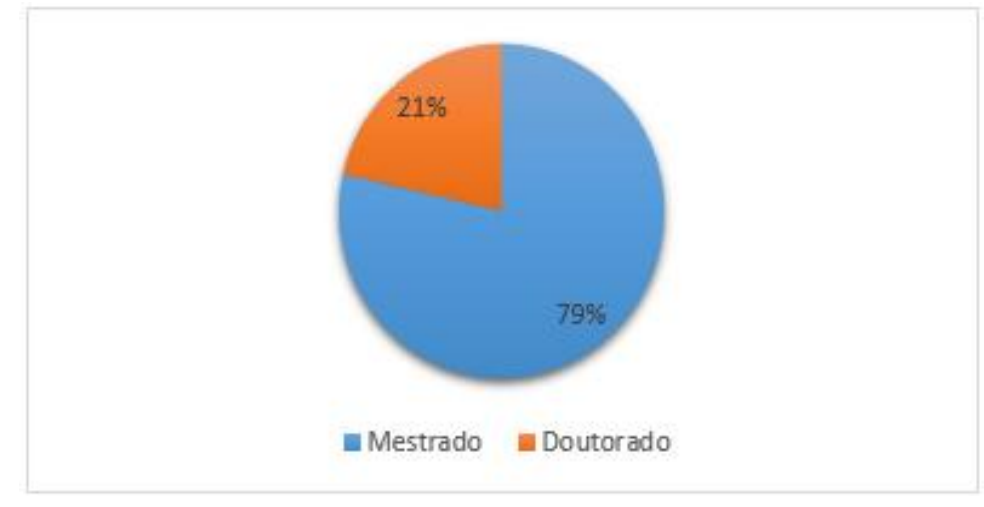

Figura 2 - Distribuição dos trabalhos por nível (Mestrado e Doutorado)

A distribuição dos 14 trabalhos de mestrado e doutorado por área de concentração dos programas de pós-graduação revelou que a maioria está vinculada à programa da área Educação (8 trabalhos), seguida pela área de Educação Especial (2 trabalhos). Também foram encontrado trabalhos publicados nos Programas de Psicologia, Letras, Teologia e Desenvolvimento Regional e Meio Ambiente, cada área com 1 trabalho publicado. Os dados revelam que a área da Educação e Educação Especial começaram a se interessar pela temática. 


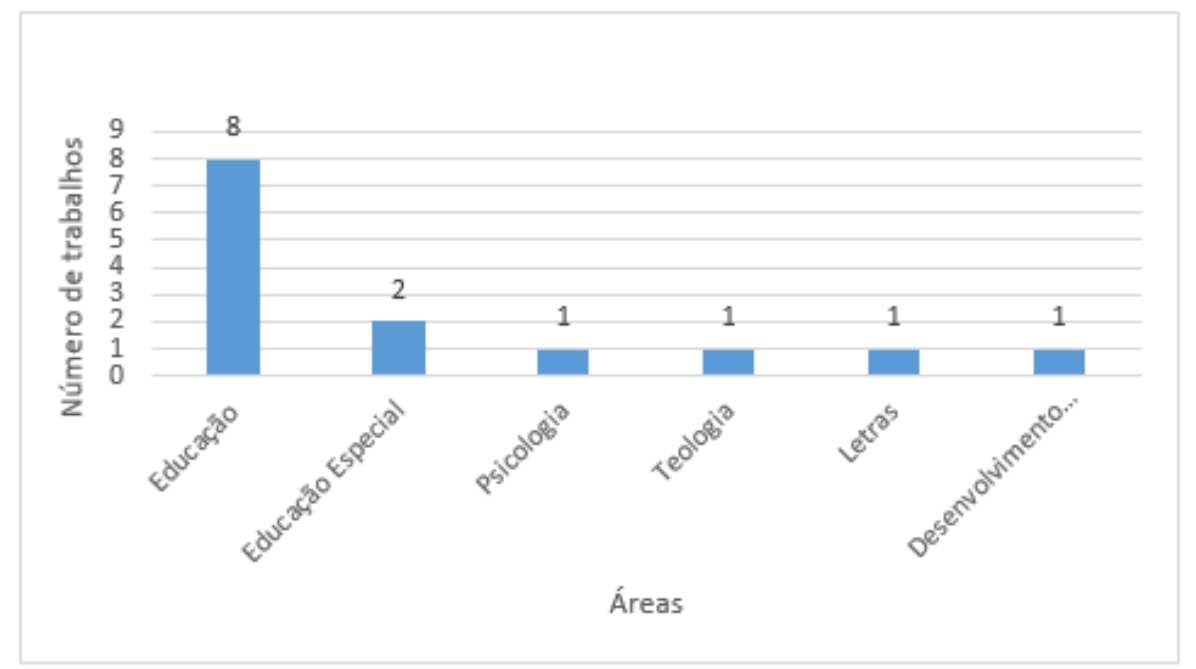

Figura 3 - Distribuição das dissertações e teses por área de concentração

Com relação as instituições que os trabalhos de mestrado e doutorado foram defendidos (figura 3), elas totalizam 7 e a maior concentração está na Universidade Federal da Grande Dourados - UFGD (7 trabalhos), seguida pela Universidade Federal de São Carlos - UFSCar (2 trabalhos), as demais instituições tiveram 1 trabalho publicado cada. Este resultado revela que a produção acadêmica que discute a temática pesquisada, concentra-se na região Centro-Oeste do Brasil, especificamente no Estado de Mato Grosso do Sul. Segundo dados do Instituto Brasileiro de Geografia e Estatística (IBGE), coletados no censo de 2010, este estado possui a segunda maior população indígena do país. Entretanto, a região Centro-Oeste, de acordo com dados da Capes sobre os programas de mestrado e doutorado no país, é a região que possuiu o menor número de programas e cursos. Pondera-se que o número elevado de trabalhos publicados neste estado e instituição pode estar relacionado a área de estudo e interesse de orientador. 


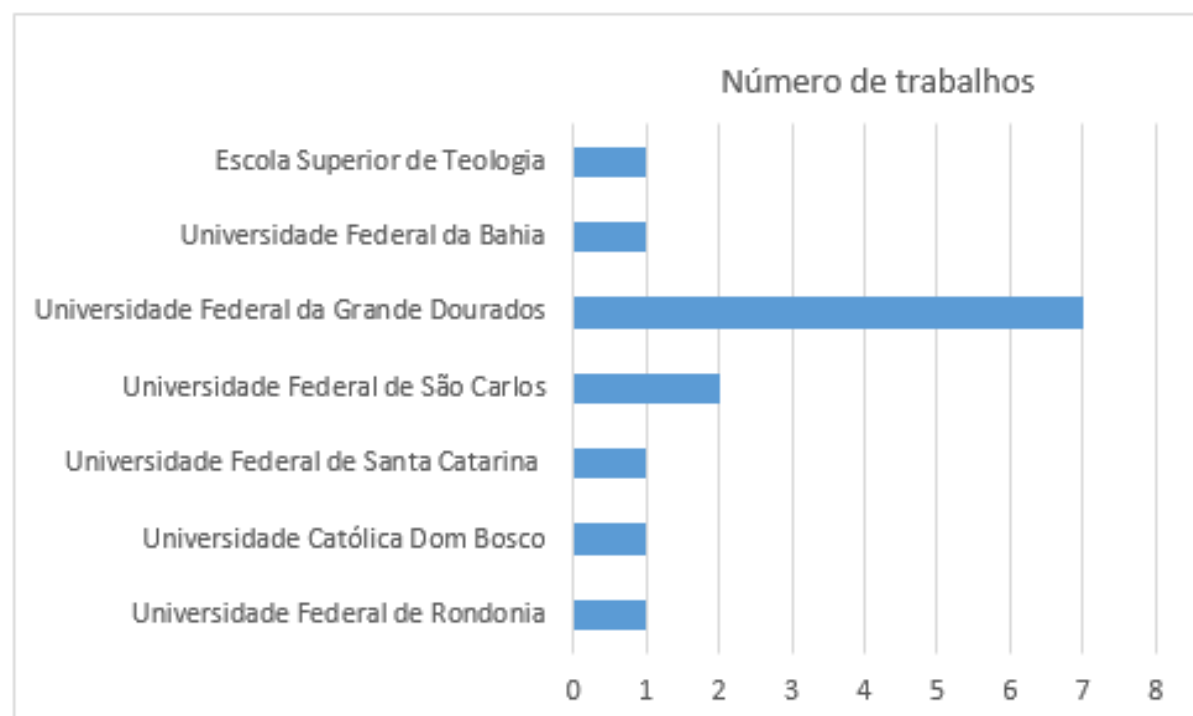

Figura 4 - Distribuição das teses e dissertações por instituição

Com relação à distribuição dos orientadores das dissertações e teses (Tabela 1), os dados apontam que Marilda Moraes Garcia Bruno docente e pesquisadora da Universidade Federal da Grande Dourados orientou o maior número de trabalhos (7). Os demais orientadores foram responsáveis por orientar um trabalho cada sobre temática proposta para este estudo.

Tabela 1 - Distribuição das dissertações e teses por orientadores e autores

\begin{tabular}{|c|c|c|c|c|}
\hline Autor & Nivel & Orientadores & Instituição & $\begin{array}{l}\text { Ano de } \\
\text { defesa }\end{array}$ \\
\hline Mario Roberto Venere & $\mathrm{M}$ & Carmen Alvarez Cruz & UFRO & 2005 \\
\hline Joselia Ferraz Soares & $\mathrm{M}$ & Sonia Grubits & UCDB & 2009 \\
\hline Shirley Vilhalva & M & $\begin{array}{lll}\begin{array}{l}\text { Ronice } \\
\text { Quadros }\end{array} & \text { Muller } & \text { de } \\
\end{array}$ & UFSC & 2009 \\
\hline Lucia Gouvea Buratto & $\mathrm{D}$ & $\begin{array}{l}\text { Maria da Piedade } \\
\text { Resende da Costa }\end{array}$ & UFSCar & 2010 \\
\hline Luciana Lopes Coelho & $\mathrm{M}$ & $\begin{array}{l}\text { Marilda Moraes Garcia } \\
\text { Bruno }\end{array}$ & UFGD & 2011 \\
\hline Michele Aparecida de Sá & M & $\begin{array}{l}\text { Marilda Moraes Garcia } \\
\text { Bruno }\end{array}$ & UFGD & 2011 \\
\hline $\begin{array}{l}\text { Vania Pereira da Silva } \\
\text { Souza }\end{array}$ & $\mathrm{M}$ & $\begin{array}{l}\text { Marilda Moraes Garcia } \\
\text { Bruno }\end{array}$ & UFGD & 2011 \\
\hline $\begin{array}{l}\text { Patrícia Carla da Hora } \\
\text { Correia }\end{array}$ & $\bar{D}$ & $\begin{array}{l}\text { Theresinha Guimarães } \\
\text { Miranda }\end{array}$ & UFBA & 2013 \\
\hline $\begin{array}{l}\text { Juliana Maria da Silva } \\
\text { Lima }\end{array}$ & $\mathrm{M}$ & $\begin{array}{l}\text { Marilda Moraes Garcia } \\
\text { Bruno }\end{array}$ & UFGD & 2013 \\
\hline $\begin{array}{l}\text { Maria do Carmo } \\
\text { Encarnação Costa } \\
\text { Souza }\end{array}$ & M & $\begin{array}{l}\text { Marilda Moraes Garcia } \\
\text { Bruno }\end{array}$ & UFGD & 2013 \\
\hline
\end{tabular}




\begin{tabular}{l|c|l|l|l}
\hline $\begin{array}{l}\text { Darcimar Souza } \\
\text { Rodrigues }\end{array}$ & M & Roberto Ervino Zwetsch & $\begin{array}{l}\text { Escola Superior } \\
\text { de Teologia }\end{array}$ & 2014 \\
\hline João Henrique da Silva & M & $\begin{array}{l}\text { Marilda Moraes Garcia } \\
\text { Bruno }\end{array}$ & UFGD & 2014 \\
\hline Michele Aparecida de Sá & D & $\begin{array}{l}\text { Katia Regina Moreno } \\
\text { Caiado }\end{array}$ & UFSCar & 2015 \\
\hline Maria Goretti da Silva & M & $\begin{array}{l}\text { Marilda Moraes Garcia } \\
\text { Bruno }\end{array}$ & UFGD & 2016 \\
\hline
\end{tabular}

Fonte: Elaboração própria com base nos dados do Catálogo de Teses e Dissertações da Capes

Com relação aos trabalhos orientados pela pesquisadora Marilda Moraes Gracia Bruno, podemos verificar que todos foram orientados no nível de mestrado e abordaram os mais diversificados temas sobre a interface da educação especial com a educação escolar indígena, como podemos verificar na tabela 2:

Tabela 2 - Distribuição dos trabalhos orientados pela pesquisadora Marilda Moraes Garcia Bruno

\begin{tabular}{|c|c|c|}
\hline Orientado(a) & Nivel & Titulo \\
\hline $\begin{array}{l}\text { Luciana Lopes } \\
\text { Coelho }\end{array}$ & M & $\begin{array}{lcccc}\text { A CONSTITUIÇÃO } & \text { DO } & \text { SUJEITO } & \text { SURDO NA } & \text { CULTURA } \\
\text { GUARANI-KAIOWÁ: } & \text { OS } & \text { PROCESSOS PRÓPRIOS } & \text { DE } \\
\text { INTERACÃO E COMUNICACÃO NA FAMÍLIA E NA ESCOLA } & \end{array}$ \\
\hline $\begin{array}{l}\text { Michele } \\
\text { Aparecida de Sá }\end{array}$ & $\mathrm{M}$ & $\begin{array}{l}\text { O ESCOLAR INDÍGENA COM DEFICIÊNCIA VISUAL NA REGIÃO } \\
\text { DA GRANDE DOURADOS, MS: UM ESTUDO SOBRE A } \\
\text { EFETIVAÇÃO DO DIREITO Â EDUCAÇÃO }\end{array}$ \\
\hline $\begin{array}{l}\text { Vania Pereira da } \\
\text { Silva Souza }\end{array}$ & $\mathrm{M}$ & $\begin{array}{l}\text { CRIANÇAS INDÍGENAS KAIOWÁ E GUARANI: UM ESTUDO } \\
\text { SOBRE AS REPRESENTAÇÕES SOCIAIS DA DEFICIÊNCIA E O } \\
\text { ACESSO ÀS POLİTICAS DE SAÚDE E EDUCAÇÃO }\end{array}$ \\
\hline $\begin{array}{l}\text { Juliana Maria } \\
\text { da Silva Lima }\end{array}$ & $\mathrm{M}$ & $\begin{array}{l}\text { A CRIANÇA INDÍGENA SURDA NA CULTURA GUARANI- } \\
\text { KAIOWÁ: UM ESTUDO SOBRE AS FORMAS DE COMUNICAÇÃO } \\
\text { E INCLUSÃO NA FAMÍLIA E NA ESCOLA }\end{array}$ \\
\hline $\begin{array}{l}\text { Maria do Carmo } \\
\text { da Encarnação } \\
\text { Costa de Souza }\end{array}$ & $\mathrm{M}$ & $\begin{array}{lcccc}\text { A ORGANIZAÇÃO DO } & \text { ATENDIMENTO EDUCACIONAL } \\
\text { ESPECIALIZADO NAS ALDEIAS INDIGENAS } & \text { DE } \\
\text { DOURADOS/MS: UM ESTUDO SOBRE AS SALAS } & \text { DE } \\
\text { RECURSOS MULTIFUNCIONAIS PARA A ÁREA DA SURDEZ } & \end{array}$ \\
\hline $\begin{array}{l}\text { João Henrique } \\
\text { da Silva }\end{array}$ & $\mathrm{M}$ & 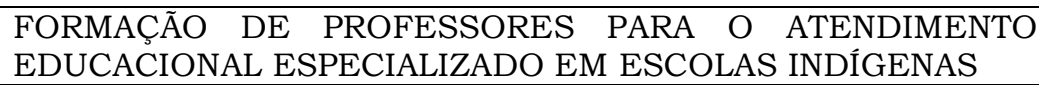 \\
\hline $\begin{array}{l}\text { Maria Goretti da } \\
\text { Silva }\end{array}$ & $\mathrm{M}$ & $\begin{array}{l}\text { IDENTIFICAÇÃO E AVALIAÇÃO FUNCIONAL DE CRIANÇAS } \\
\text { INDÍGENAS KAIOWÁ E GUARANI COM DEFICIENCIA VISUAL E } \\
\text { PARALISIA CEREBRAL DE O A } 5 \text { ANOS }\end{array}$ \\
\hline
\end{tabular}

Fonte: Elaboração própria com base nos dados do Catálogo de Teses e Dissertações da Capes

Os trabalhos orientados pela pesquisadora Marilda Moraes Garcia Bruno e defendidos por Luciana Lopes Coelho, Juliana Maria da Silva Lima e Maria do Carmo da Encarnação Costa de Souza se debruçaram, de modo geral, a estudar a surdez dentro das comunidades indigenas da Região da 
Grande Dourados. No caso do trabalho de Luciana Lopes Coelho investigou a constituição do sujeito surdo na cultura Guarani-Kaiowá e os processos de interação e comunicação na família e na escola. O trabalho de Juliana Maria da Silva Lima investigou as formas de comunicação e inclusão da criança surda indigena no contexto familiar e escolar de duas aldeias indígenas do município de Dourados/MS. E o trabalho de Maria do Carmo da Encarnação Costa de Souza se propôs a analisar a oferta do Atendimento Educacional Especializado para surdos nas Salas de Recursos Multifuncionais no contexto das escolas indígenas do Município de Dourados/MS.

Os trabalhos de Michele Aparecida de Sá e Maria Goretti da Silva, orientados pela pesquisadora, estudaram a deficiência visual nas comunidades indigenas. No caso do trabalho de Michele Aparecida de Sá teve como objetivo identificar os alunos com deficiência visual e as ações da gestão educacional para o atendimento às necessidades educacionais especiais da população indigena com deficiência visual. O trabalho de Maria Goretti da Silva objetivou avaliar a visão funcional e o desenvolvimento global de crianças indígenas Kaiowá e Guarani com deficiência visual e paralisia cerebral na faixa etária de zero a cinco anos nas aldeias de Dourados/MS.

Os trabalhos dos orientados João Henrique da Silva e Maria do Carmo da Encarnação Costa de Souza, este último citado anteriormente no tema surdez, debruçaram a estudar o atendimento educacional especializado dentro das comunidades indígenas. O trabalho de João Henrique da Silva objetivou desenvolver, em conjunto com os professores que atuam no AEE das escolas indígenas de Dourados/MS, um programa de formação continuada para investigar as ações pedagógicas presentes nas Secretaria de Educação e analisar os impasses, os obstáculos e os desafios do AEE e da inclusão escolar. E o trabalho de Maria do Carmo da Encarnação Costa de Souza analisou a ofertado do AEE para surdos nas Salas de Recursos Multifuncionais no contexto das escolas indígenas do Município de Dourados/MS.

Por fim, o trabalho da orientada Vania Pereira da Silva Souza teve como tema central investigar a infância e as condições de vida da criança indigena Kaiowá e Guarani, com deficiência, em aldeias da Região da Grande Dourados, 
buscando mapear as políticas sociais e o acesso à saúde e à educação nas aldeias.

Além de orientar as produções acadêmicas stricto sensu, Marilda Moraes Garcia Bruno coordenou o projeto de extensão "Identificação e Prevenção da Deficiência Visual nas Aldeias de Dourados" no período de 2007 a 2009, cujo objetivo foi a formação continuada de professores indigenas e agentes comunitários para a triagem ocular de alunos das escolas das aldeias da Região da Grande Dourados/MS.

No período de 2009 a 2016 coordenou o projeto de pesquisa "Mapeamento de deficiências na população indígena da Região da Grande Dourados, MS: Um estudo sobre os impactos e as possiveis implicações para a inclusão educacional", neste projeto teve 9 alunos de mestrado envolvidos e 2 da graduação. Desde 2015 coordena o projeto de pesquisa intitulado "Politica, Gestão e Práticas de Educação Especial na educação básica: um estudo sobre as configurações, impactos e desafios em diferentes contextos", o qual apresenta como foco a interface entre a educação especial e a educação do campo, a educação dos povos indígenas com deficiência e de grupos sociais e identitários estigmatizados. Podemos considerar que os projetos desenvolvidos pela pesquisadora foram pioneiros na interface da educação especial na educação escolar indígena.

Marilda Moraes Garcia Bruno também publicou diversos artigos científicos e organizou dois livros que tratam sobre a temática, sendo eles "Educação, Diversidade e Fronteiras da In/Exclusão" (2012) e "Educação Escolar Indígena, Diferença e Deficiência: (re)pensando práticas pedagógicas" (2015). De modo geral verifica-se que a pesquisadora contribuiu significativamente para ampliação e divulgação dos estudos sobre a interface da educação especial na educação escolar indígena.

\section{Considerações finais}

A professora e pesquisadora Marilda Moraes Garcia trouxe contribuições significativas para a área da educação e para a vida das pessoas com deficiência. Há mais de 30 anos desenvolve seus estudos na área da 
educação especial e defende a inclusão escolar antes mesmo dessa discussão virar pauta das políticas públicas de educação. Como exemplo, podemos citar o livro publicado no ano de 1986 com o título "O deficiente visual na classe comum". Nesta obra Marilda evidenciou que a educação escolar da pessoa com deficiência visual devia ser realizada no ensino regular, discussão essa inovadora num momento em que se defendia a integração escolar para as pessoas com deficiência.

Com relação a interface das áreas da educação especial com a educação escolar indigena, esta pesquisadora foi uma das pioneiras a desenvolver projetos de pesquisa e de extensão sobre a temática. A partir desses projetos foram realizados estudos de mestrado e trabalhos de Iniciação Científica que tiveram os seus resultados publicados em periódicos nacionais da área da educação e educação especial.

Como podemos observar neste estudo $50 \%$ da produção científica encontrada, produzida em programas de pós-graduação stricto sensu, sobre a temática da interface da educação especial na educação escolar indígena, teve influência e orientação da pesquisadora Marilda Moraes Garcia Bruno. Assim, podemos concluir que essa pesquisadora contribuiu para a abertura das discussões sobre a temática e deu visibilidade na ciência a um público (indígenas com deficiência) que antes era invisível perante a academia e as políticas públicas.

\section{Referências}

BRASIL. Constituição. Constituição da República Federativa do Brasil de 1988. Brasília DF: Senado, 1999.

Lei $\mathrm{n}^{\circ} .9 .394$, de 20 de dezembro de1996. Estabelece as diretrizes e bases da educação nacional. Diário Oficial da República Federativa do Brasil, Brasília, DF, n. 248, 23 de dez. 1996.

Portaria $n^{\circ}$ 948, de 09 de outubro de 2007. Dispõe sobre Política 
Nacional de Educação Especial na Perspectiva da Educação Inclusiva. Brasília, DF, 2008.

Ministério de Educação e do Desporto. Secretaria de Educação Fundamental. Referencial curricular nacional para as escolas indigenas. Brasília, DF: MEC/SEF, 1998.

. Ministério da Educação. Secretaria de Educação Básica. Diretrizes Curriculares Nacionais para a Educação Escolar Indigena. Brasília, DF: MEC, SEB, DICEI, 2013.

Lei $n^{\circ} .9 .394$, de 20 de dezembro de1996. Estabelece as diretrizes e bases da educação nacional. Diário Oficial da República Federativa do Brasil, Brasília, DF, n. 248, 23 de dez. 1996.

Plano Nacional de Educação 2014-2024 [recurso eletrônico]: Lei $n^{o}$ 13.005, de 25 de junho de 2014, que aprova o Plano Nacional de Educação (PNE) e dá outras providências. Brasília: Câmara dos Deputados, Edições Câmara, 2014. Disponível em: < http: / / www.observatoriodopne.org.br/uploads/reference/file/439/documen to-referencia.pdf>. Acessado em: 02 abr. 2018.

. Instituto Brasileiro de Geografia e Estatística. Censo demográfico 2010. Brasília: IBGE, 2010.

. Ministério da Educação. Secretaria de Educação Básica. Diretrizes Curriculares Nacionais para a Educação Escolar Indigena. Brasília, DF: MEC, SEB, DICEI, 2013.

Declaração de Salamanca e Linha de Ação sobre necessidades educacionais especiais. Tradução: Edílson Alkmim da Cunha. 2. ed Brasília: CORDE, 1997.

. Decreto 6949, de 25 de agosto de 2009. Disponivel em:

<http://www.planalto.gov.br/ ccivil_03/_Ato2007-

2010/2009/Decreto/D6949.htm>. Acesso em: 03 jul. 2018.

BRUNO, M. M. G.; ALL., Y. C. E. . O Deficiente Visual na classe comum. São Paulo SP: SE/SEE/CENP/SP, 1986. 
COELHO, L. L. A constituição do sujeito surdo na cultura Guarani-Kaiowá: Os processos próprios de interação e comunicação na família e na escola. $153 \mathrm{f}$. Dourados, 2011. Dissertação (Mestrado em Educação). Universidade Federal da Grande Dourados, 2011.

HAYASHI, M. C. P. I. et al. Competências informacionais para utilização da análise bibliométrica em educação e educação especial. Educação Temática Digital. Campinas, v.7, n.1, 2005, p.11-27.

LIMA, J. M. S. A criança indigena surda na cultura Guarani-Kaiowá: um estudo sobre as formas de comunicação e inclusão na família e na escola. 172 f. Dourados, 2011. Dissertação (Mestrado em Educação). Universidade Federal da Grande Dourados, 2013.

MAZZOTTA, M. J. S. Educação Especial no Brasil: História e politicas públicas. 5. ed., São Paulo, SP: Cortez, 2005.

SÁ, M. A. O escolar indigena com deficiência visual na Região da Grande Dourados, MS: um estudo sobre a efetivação do direito à educação. $135 \mathrm{f}$. Dourados, 2011. Dissertação (Mestrado em Educação). Universidade Federal da Grande Dourados, 2011.

SILVA, J. H. da. Formação de professores para o Atendimento Educacional Especializado em escolas indigenas. 205 f. Dourados, 2014. Dissertação (Mestrado em Educação). Universidade Federal da Grande Dourados, 2014.

SILVA, M. G. Identificação e avaliação funcional de crianças indigenas Kaiowá e Guarani com deficiência visual e paralisia cerebral de 0 a 5 anos. 149 f. Dissertação (Mestrado em Educação). Universidade Federal da Grande Dourados, 2016.

SOUZA, M. C. E. C. A organização do Atendimento Educacional Especializado nas aldeias indigenas de Dourados/MS: Um estudo sobre as salas de recurso multifuncionais para a área da surdez. $155 \mathrm{f}$. Dissertação (Mestrado em Educação). Universidade Federal da Grande Dourados, 2013.

SOUZA, V. P. S. Crianças indigenas Kaiowá e Guarani: Um estudo sobre as representações sociais da deficiência e o acesso às políticas de saúde $e$ educação em aldeias da região da Grande Dourados. 155f. Dourados, 2011. Dissertação (Mestrado em Educação). Universidade Federal da Grande Dourados, 2011. 